\title{
Real-time monitoring of the rubber belt tension in an industrial conveyor
}

\author{
Damian Bzinkowski ${ }^{1}$, Tomasz Ryba ${ }^{2}$, Zbigniew Siemiatkowski ${ }^{3}$, Miroslaw Rucki ${ }^{4}$ \\ ${ }^{1}$ Kazimierz Pulaski University of Technology and Humanities in Radom, Poland, e-mail: damianbzinkowski@gmail.com \\ ${ }^{2}$ Sieć Badawcza Łukasiewicz, Instytut Technologii Ekspoatacji w Radomiu, Poland, e-mail: \\ tomasz.ryba@itee.lukasiewicz.gov.pl \\ ${ }^{3}$ Kazimierz Pulaski University of Technology and Humanities in Radom, Poland, e-mail: z.siemiatkowski@uthrad.pl \\ ${ }^{4}$ Kazimierz Pulaski University of Technology and Humanities in Radom, Poland, e-mail: m.rucki@uthrad.pl
}

\section{Article Info}

Article history:

Received September 28, 2021

Revised November 5, 2021

Accepted November 15, 2021

\section{Keywords:}

Belt conveyor,

Monitoring,

Diagnostics,

Repeatability,

Uncertainty.

\begin{abstract}
The paper presents a novel system for monitoring of the work of industrial belt conveyor. It is based on the strain gauges placed directly on the roller surface that measure pressing force of the belt on the roller. Automatical operation of the measurement system minimizes impact of an operator on the measurement results. Experimental researches included the stability of indications during 5 days, Type A uncertainty estimation and equipment variation $E V$ calculations. Expanded uncertainty calculated for the level of confidence $95 \%$ was below $0.1 \%$ of the actually measured value, and percentage repeatability $\% E V=9.5 \%$ was obtained. It can be considered satisfactory, since usually it is required $\% E V<10 \%$ for new measurement systems.
\end{abstract}

Copyright (C) 2021 Regional Association for Security and crisis management and European centre for operational research. All rights reserved.

\section{Corresponding Author:}

Miroslaw Rucki,

Kazimierz Pulaski University of Technology and Humanities in Radom, Poland; email: email@email.com

\section{Introduction}

Conveyors complete the production process with the required process efficiency, since they are able to transport loose materials as well as details or conponents or even assembled units (Rybicka \& Caban, 2020). The first documented attepmts to build belt conveyors can be found in 1975 in the case of grains transportation and in 1830 for removal of the wastes after milling (Van Etten, 2017). Since then, many constructional changes were introduced to adapt the belt feeder to its new applications. Especially in industry, new solutions of the conveyors in the transportation systems help to reduce the costs (Mazurkiewicz, 2015). It is particularly important today, when the product price is often dictated by the market, and manufacturer is forced to reduce costs to ensure any profit (Jozić et al., 2021; Tyczynski et al., 2020). Researchers indicate that lack of the monitoring systems for belt conveyors can generate additional costs and interruptions in the manufacturing processes (Błażej et al., 2015).

The most recent trend in the monitoring systems is directed to their ability of the real-time data analysis and decision making, usually based on machine learning algoritms and further built into Cyber Physical Systems (CPS), that enable future realization of a Smart Factory concept (Wu et al., 2019). Virtual reality and machine learning can support the failure anaylsis of the belts and to achieve sustainability (Fedorko, 2021; Andrejiova et al., 2021). There are also examples of such a system for belt conveyor monitoring integrated with a CPS (Mörth et al., 2020). Basically, there are many critical elements in the conveyor, which can be monitored and included to a diagnostic system, such as electrical motor, driving roller, roller without driving, gearbox, joints and the belt itself (Wodecki et al., 2017). However, despite many proposals on the 
devices designed to collect reliable signals during the work of the belt conveyor, no satisfactory measurement system was built yet. Perhaps, among the main reasons can be named high requirements for the demanding belt conveyors (Noack et al., 2017). Among the systems built for the belt conveyors monitoring, multispectral visual inspection was proposed (Hou et al. 2019), audio noise measurement (Yang et al., 2020), gearbox temperature measurement (Grzesiek et al., 2020), and measurement of changing magnetic field generated around defects in the magnetized steel cord (Błażej et al., 2018), as well as probabilistic models (Semrad et al., 2020). However, existing methods are either involving advanced devices and thus very expensive, or provide signals of low reliability.

In the present work, a novel solution is proposed that is based on cheap strain gauges, but is able to fulfil requirements of the monitoring system. In particular, attention was paid to possibility of adaptation of the system to the existing and workich belt conveyor systems, collection and processing data in the real time, reliable construction and measurement characteristics, and environmet-friendly technological solutions.

\section{Concept of the measuring system}

Belt conveyors usually consist of conveyor modules with and without drive, support and drive elements that are subjected to variable loads from the transported loads (Rybicka \& Caban, 2020). Concept of the measuring system able to perform real-time monitoring of the belt tension is based on the strain gauges placed directly on the roller. Figure 1 presents the prototype, where the belt (3) is placed on the roller (4) with certain pressing force $F_{b}$. Sets of the strain gauges (2) on the roller surface are subject of this pressure, too. Inside the roller, systems of current supply and the signal receivers and transmitters (1) are placed as a Printed Circuit Board (PCB), with fixations projected and printed using Additive Manufacturing technology. The measurement data is received by the computer (5), which also transmits control signals.

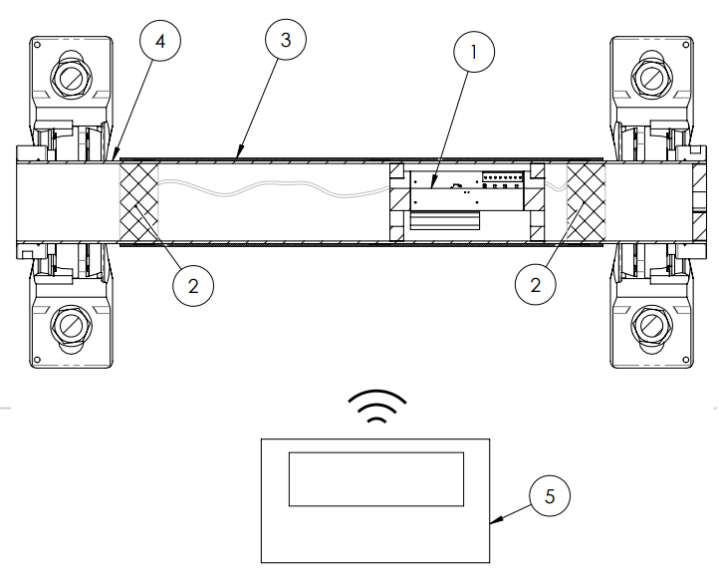

Figure 1. Scheme of the measuring system for real-time monitoring of the belt tension, 1 receiving and transmitting system, 2 - set of the strain gauges, 3 - feeder belt, 4 - roller, 5 computer with the dedicated software.

The measurement data is generated by the strain gauges providing information on the work of industrial feeder. It was assumed that the strain gauges placed along the roller would be able to indicate failures, e.g. local disruption of the belt or its displacement, preventing breakdown of the entire mechanism. Moreover, in further stages of development, it is expected to derive form the measurement signal a wide range of the deviations from the normal work of the monitored feeder and its critical states.

It was assumed that the main concept of information system for belt conveyor monitoring proposed by (Jeinsch et al., 2000) could be applied with some necessary modifications. In particular, signals on the force $F$ collected from the strain gauges and further processed should be correlated with rotational speed $n$ and with actual load $Q$, as it is shown in Figure 2. 


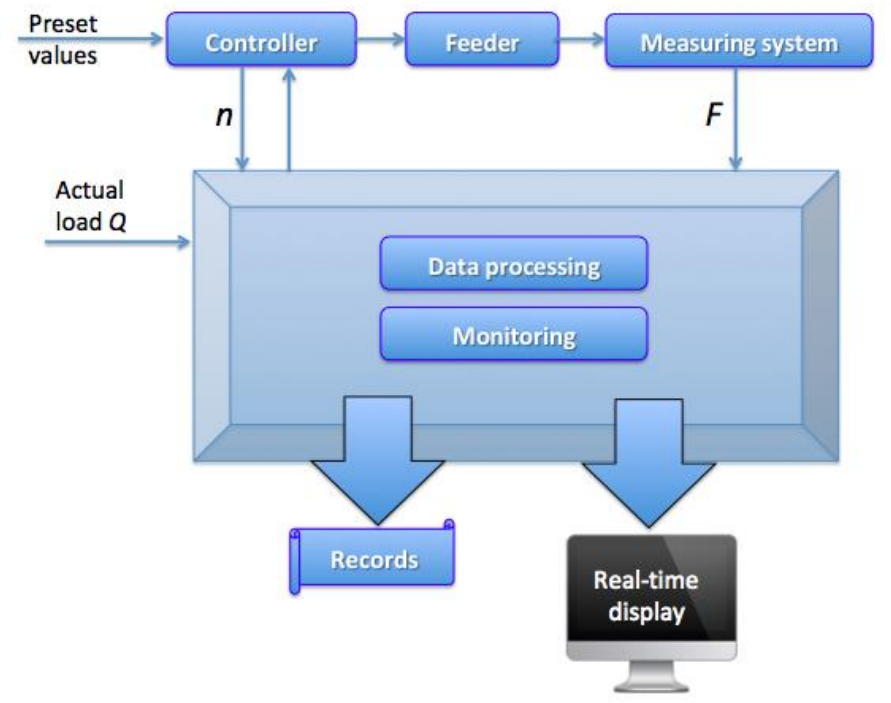

Figure 2. Schematic of the information flow in the developed system

In the measurement system, three strain gauges CP $152 \mathrm{NS}$ were applied, placed along the roller. Diameter of their working area was $\varnothing 16 \mathrm{~mm}$, which was found optimal after the initial tests (Ryba, 2021). Small dimensions and mass were important features that made strain gauges suitable for the pressing force measurement on the roller surface. They performed high sensitivity of $0.8-0.8 \mathrm{mV} / \mathrm{V}$, high sampling frequency up to $20,000 \mathrm{~Hz}$, and a very short response time ca. $5 \mu \mathrm{s}$. It should be noted that the sensors' time constants of few miliseconds are sufficient for the real-time monitoring (Rucki, 2020). The strain gauges connected with an electronic system form the measurement system able to collect data on the belt pressing force $F$, to transmit them through bluetooth port and to process it using the computer with a dedicated program based on LabView software. Figure 3 contains the block diagram of control and data collection algorithm realized by the measurement system. Further development of the system in the frames of Industry 4.0 will utilize Machine Learning based on Big Data collected from the long working time of many devices (Zhang et al., 2021).

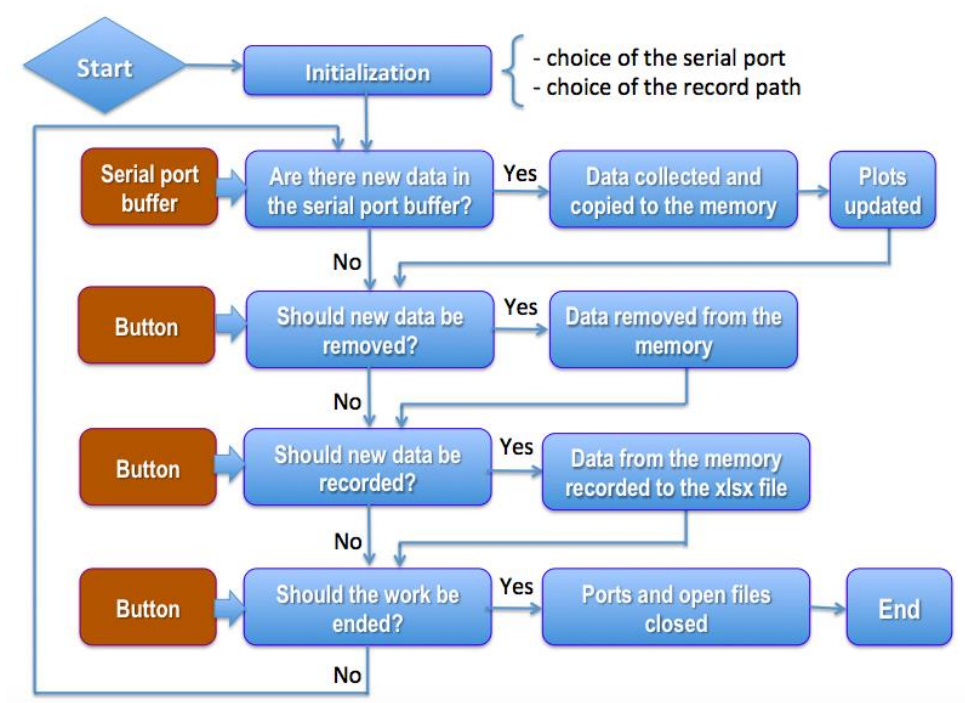

Figure 3. Control and data collection algorithm.

It is convenient to distinguish between the electronic unit and the mechanical one. The electronic unit consists of strain gauges, receiving and transmitting system, and computer with the dedicated software. The mechanical unit is in fact a test rig making possible to imitate working conditions of a belt monitoring system. It consists of two rollers with a robber belt with functions of belt velocity control and belt tension 
adjustment. The belt used in the test rig was of high quality, type EDV08PB-AS 2.0 with two inner layers and the PVC outer coating on the one side. Main technical parameters of the belt are collected in Table 1.

Table 1. Technical parameters of the belt used in the test rig

\begin{tabular}{cc}
\hline Parameter & Value \\
\hline Belt thickness & $2 \mathrm{~mm}$ \\
Minimal roller diameter $d_{\min }$ & $30 \mathrm{~mm}$ \\
Inner working force $F 1 \%$ & $8 \mathrm{~N} / \mathrm{mm}$ \\
Working temperature & $-10 \ldots 80^{\circ} \mathrm{C}$ \\
\hline
\end{tabular}

On the surface of one roller, the strain gauges are placed, making an interconnection between mechanical and electronic units. This dependence is shown schematically in Fig. 4, with mechanical unit generating various pressures from the belt on the roller and strain gauges, and electronic unit collecting, transmitting and processing the relevant signals, presenting them in form of graphs and tables with results.

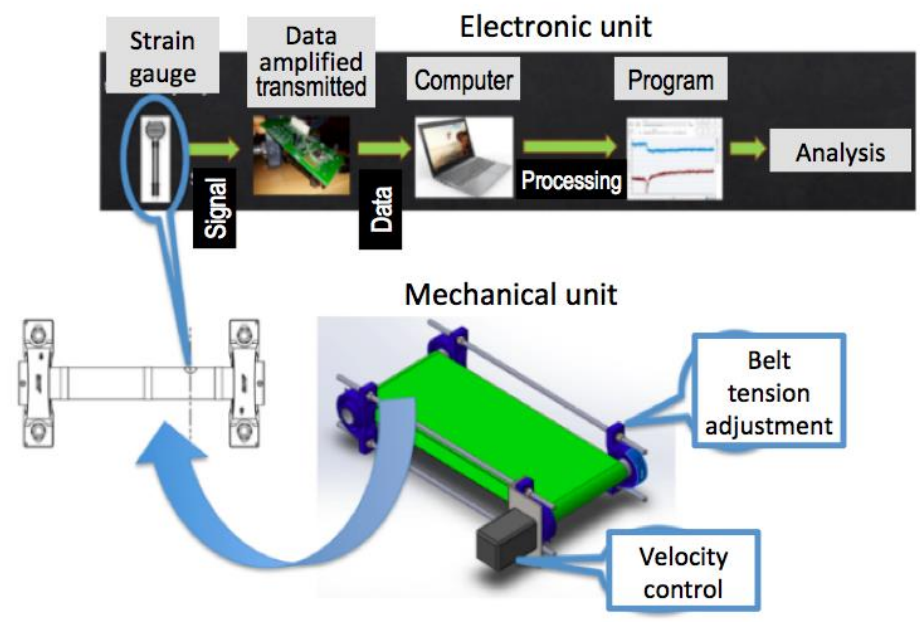

Figure 4. Electronic and mechanical units of the belt tension monitoring system test rig

Since the strain gauges are placed on the one side of the roller, they would emit signals of pressure only when directly under the belt. It can be expected that during normal work of the belt feeder, signals would follow certain predictable pattern. For instance, when there is no load on the belt, each rotation woild give a pulse of pressure on the strain gauge generating relevant cyclic signal of approximately the same value, as it is shown in Figure 5a. However, when a load of certain weight is placed on the belt, the pressure on the roller will increase when the load is approaching the roller with strain gauges, as it is shown in Figure 5b.

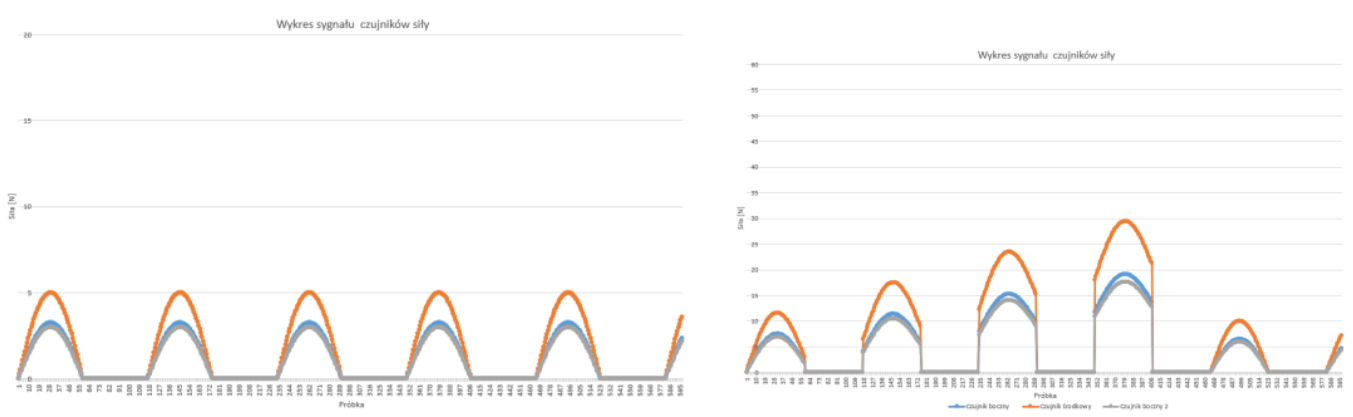

Figure 5. Simulated signals from the strain gauges during work of the belt feeder: (a) Without load; (b) When a load is placed on the moving belt.

In fact, the pressure indicated by the strain gauges will not depend only on the initially set belt tension and the load value. Complex phenomena of stress distribution inside the robber belt can be expected to generate variety of deviations from the simulated values shown in the idealized Figure 5. 


\section{Experimental}

\subsection{Measurement conditions}

To minimize effect of uncertainty propagation, the calibration procedure was performed in Radwag laboratory (Radom, Poland) for each strain gauge. The expanded uncertainty of strain gauges conductance was $U 0.99=0.75[\mu \mathrm{S}]$, for the level of confidence $99 \%$, while the maximal approximation error was ca. $8 \%$ (Rucki et al., 2020).

Moreover, runout of bearings of the rollers was checked. For thrre bearings, runout was $\pm 0.03 \mathrm{~mm}$, while for the fourth one it was $\pm 0.04 \mathrm{~mm}$. These values were found negligible from the perspective of the effect on the belt tension measurement.

The experiments were performed using the test rig in the Laboratory of Production Processes Automation of the Faculty of Mechanical Engineering UTH Radom (Poland). The tests were performed in order to check stability and repeatability of the system in real-time working conditions.

\subsection{Measurement signals}

Data processing requires thorough understanding of the registered signal. In the investigated application, the signal value is determined by the conditions how it is generated. The example of the measurement signal structure is shown in Figure 6.

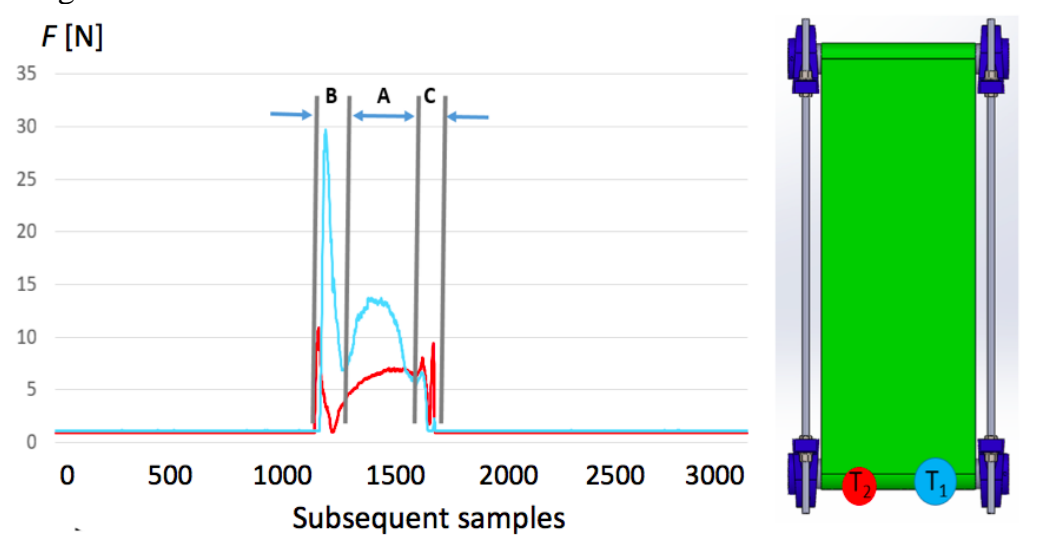

Figure 6. Measurement signal obtained from two strain gauges.

The pattern of the measurement signal of each strain gauge is essentially the same. It is generated only when the strain gauge is directly under the belt pressure, i.e. at the angle $\theta=180^{\circ}$ of the rotation of the roller. It should be noted, however, that when the belt starts and finishes pressing the gauge, some sort of peaks is generated, marked B and C in Figure 6.

Before filtering the pressure signal, the usability of its parameters was investigated. Two force signals wer edistinguished, $F_{\max 1}$ for the first peak and $F_{\max 2}$ for the second one, as it is shown in Figure 7a. Figure $7 \mathrm{~b}$ shows the pressing force indications collected for 50 subsequent revolutions of the roller. Statisctical parameters of the signal are shown in Table 2.
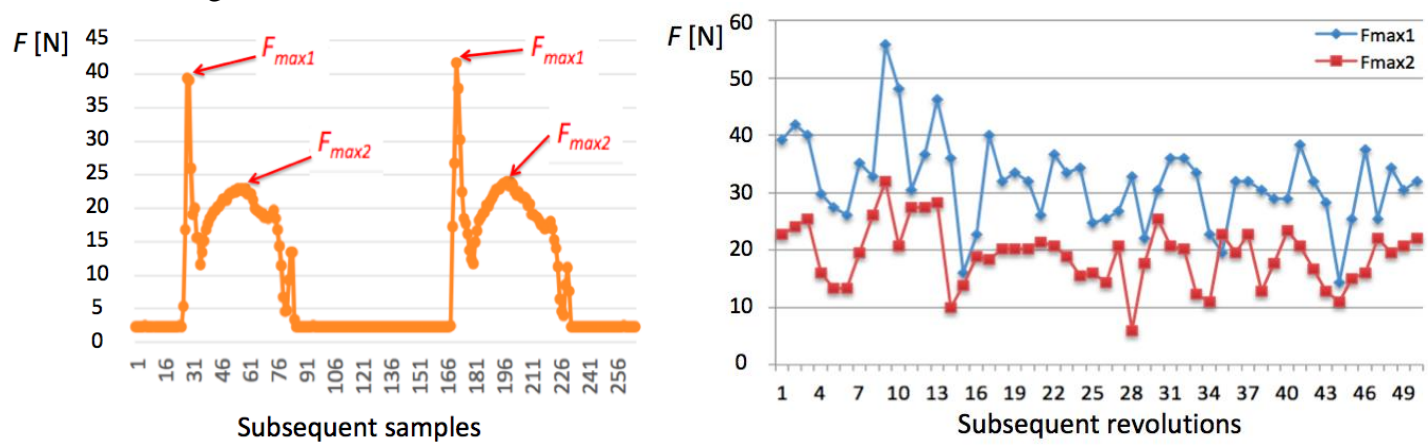

Figure 7. Measurement signals obtained from the strain gauge placed in the middle of the roller length: (a) Two analyzed peaks $F_{\max 1}$ and $F_{\max 2}$; (b) Values registered at rotational speed $400 \mathrm{rev} / \mathrm{min}$. 
Table 2. Statistics for signals obtained from the strain gauge placed in the middle of the roller length, at rotational speed $f=400 \mathrm{rev} / \mathrm{min}$.

\begin{tabular}{cccc}
\hline & $F_{\max 1}[\mathrm{~N}]$ & $F_{\max 2}[\mathrm{~N}]$ & difference $[\%]$ \\
\hline Average & 31.9 & 19.1 & 59 \\
Max & 55.8 & 32.0 & 57 \\
Min & 14.4 & 6.0 & 43 \\
$R=$ Max - Min & 4.1 & 2.6 & 63 \\
St. Deviation & 7.61 & 5.23 & 69 \\
\hline
\end{tabular}

Figure $7 \mathrm{~b}$ shows that the general trend of the signals $F_{\max 1}$ and $F_{\max 2}$ was the same. It was found, however, that the peak $F_{\max 1}$ exhibited not only higher values than $F_{\max 2}$, but also larger dispersion and range. In general, values for $F_{\max 2}$ comprised ca. $60 \%$ of that for $F_{\max 1}$, which indicated that $F_{\max 2}$ signal is enough for further analysis and $F_{\max 1}$ can be filtered out.

\subsection{Initial tension}

In the test rig, the belt tension can be adjusted with two screws shown in Figure 4. Initial tension of the belt was adjusted using signals from two strain gauges $T_{1}$ and $T_{3}$ placed close to the sides of the roller. The gauge $T_{2}$ in the middle had to be omitted in this procedure, since its signal is always dependent on the uniformity of the belt tension. Its value is always higher than that of $T_{1}$ and $T_{3}$, so the purpose of tension adjustment is in fact to obtain similar force indication from these two strain gauges. It does not matter, which one is adjusted first, because the indication of the second strain gauge can be always made similar. In Figures $8 \mathrm{a}$ and $8 \mathrm{~b}$, there are examples of the initial tension adjustment using as a reference indications of $T_{1}$ and $T_{3}$, respectively.
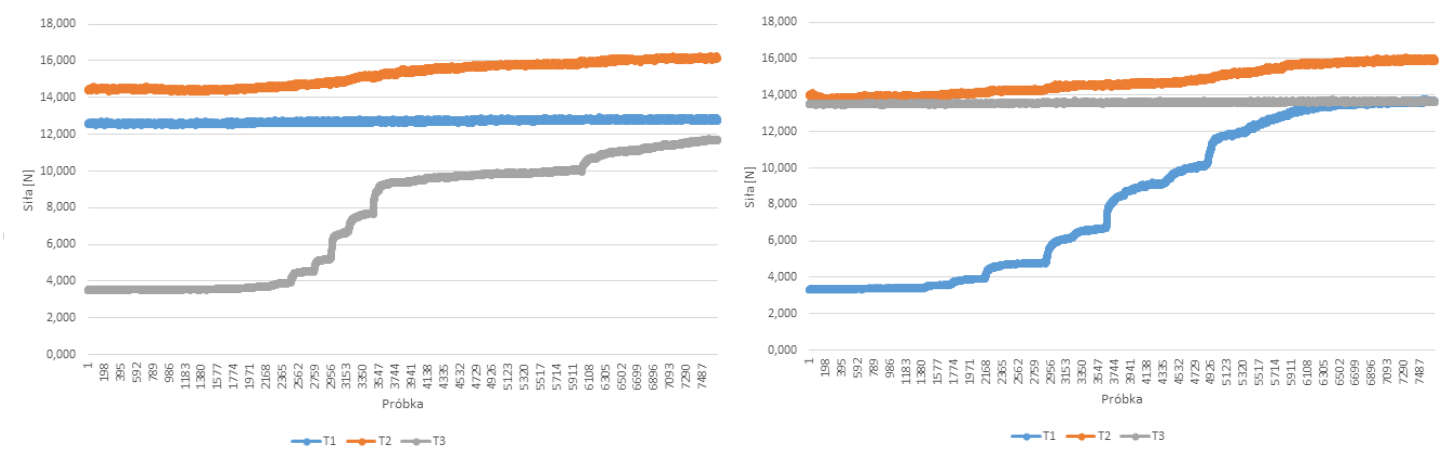

Figure 8. Adjustment of the belt tension: (a) Using $T_{1}$ as a reference; (b) Using $T_{2}$ as a reference.

The strain gauge $T_{2}$ in the middle of the roller length reveals increase of the belt tension in much smaller degree than it is seen in the actually adjusted side as indicated by $T_{1}$ or $T_{3}$. However, it can be seen that the reference strain gauge, namely $T_{1}$ in Figure $8 \mathrm{a}$ and $T_{3}$ in Figure 8b, indicated only slight increase of the belt tension. Due to this finding, it can be stated that after setting initial belt tension on the one side, the respective strain gauge can be used as a reference for the other side adjustment. This way our system solved a range of problems with belt tension known in the research literature (Zhao \& Lin, 2011) and with monitoring of the belt mistracking (Kobayashi \& Toya, 2007).

\section{Results and discussion}

\subsection{Stability of the system}

Stability results were obtained for the belt tension static measurement during 5 subsequent days as shown in Figure 9. Each measurement had Type A uncertainty (JCGM, 2008) estimated from 100 samples taken in repeatability conditions. Standard deviations, which is also standard uncertainty, was calculated as $0.0157 \mathrm{~N}$, $0.0176 \mathrm{~N}$, and $0.0134 \mathrm{~N}$ for the strain gauges $T_{1}, T_{2}$, and $T_{3}$, respectively. Thus, maximal value of the expanded uncertainty calculated for the level of confidence $95 \%$ with coverage factor $k_{U}=1.96$ was $U_{95}=0.034 \mathrm{~N}$. 


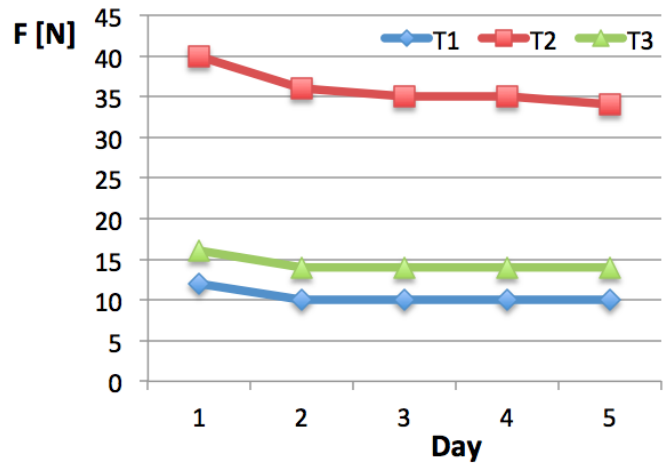

Figure 9. Changes of the static belt tension during 5 subsequent days.

Graphs in Figure 9 revealed maximal decrease of the belt tension $8.89 \mathrm{~N}$ registered by the strain gauge $T_{2}$ situated in the middle of the roller length. Uncertainty estimation confirmed that it was caused not by the measurement system, but by the relaxation processes in the belt itself. Considering that the loads and movement itself would increase values of the tension, it is obvious that after some time of work the belt tension should be adjusted again. Real-time monitoring is essential to prevent extensive decrease of the belt tension and, on the other hand, to avoid the unnecessary interruptions of the work aimed at checking, which opens the way for Predictive Maintenance implementation (Liu et al., 2019; Zenisek et al., 2021).

\subsection{Repeatability test}

Essentially, repeatability is the variation caused by the instrumentation, while the reproducibility is represented by the variation observed when different operators measure the same part with the same instrumentation (Zanobini et al., 2016). In the case of automated measurement, there is no influence of the operator, so that reproducibility component in the results variation is minimized. Repeatability can be determined as the equipment variation $(E V)$, registered when repeated measurements of the same product are performed in the same laboratory (Yeh \& Sun, 2013). Particular procedure of the $E V$ determination was taken from the literature (Dietrich \& Schultze, 2011), where the basic formula is given:

$\sum E=\sum_{i=1}^{n} \sum_{j=1}^{k}\left(X_{i j}-X_{i}\right)^{2}$

where: $X_{i} \bullet$ - arithmetic mean for the particular measurements,

$i$ - number of measuring points, from 1 to $n$; here $n=3$ corresponds with three strain gauges, $T_{1}, T_{2}$, and $T_{3}$;

$j$ - number of measurement repetitions, from 1 to $k$; here $k=30$.

Number $k=30$ allows for application of Gaussian statistics, avoiding the Student's coefficients. From that, $E V$ was calculated for the confidence level $99 \%$ using the equation (Dietrich \& Schultze, 2011):

$E V=5.15 s_{E}$,

where:

$S_{E}^{2}=\frac{1}{n(k-1)} \sum E$.

Results are presented in Table 3.

Table 3. Repetitions of the measurements for $E V$ calculations [N]

\begin{tabular}{ccccccccccccc}
\hline$j$ & 1 & 2 & 3 & 4 & 5 & 6 & 7 & 8 & 9 & 10 & $X_{i} \cdot \sum_{j=1}^{k}\left(X_{i j}-X_{i \bullet}\right)^{2}$ \\
\hline & 13.94 & 13.94 & 14.09 & 14.09 & 14.09 & 14.09 & 14.25 & 14.25 & 14.25 & 14.25 & & \\
$T_{1 j}$ & 14.25 & 14.40 & 14.56 & 14.56 & 14.56 & 14.56 & 14.56 & 14.56 & 14.56 & 14.71 & 14.53 & 3.59735 \\
& 14.71 & 14.71 & 14.87 & 15.03 & 14.87 & 15.19 & 14.87 & 15.03 & 14.87 & 14.87 & & \\
\hline & 16.99 & 16.99 & 16.99 & 17.15 & 17.15 & 17.15 & 17.15 & 17.15 & 17.15 & 17.32 & & \\
$T_{2 j}$ & 17.15 & 17.15 & 17.32 & 17.32 & 17.32 & 17.32 & 17.32 & 17.32 & 17.32 & 17.32 & 17.30 & 0.80617 \\
& 17.49 & 17.32 & 17.49 & 17.49 & 17.49 & 17.49 & 17.49 & 17.49 & 17.49 & 17.49 & & \\
\hline
\end{tabular}




\begin{tabular}{lllllllllllll}
\hline & 12.74 & 12.89 & 12.89 & 12.89 & 12.89 & 13.03 & 12.74 & 12.89 & 13.05 & 13.04 & & \\
$T_{3 j}$ & 13.19 & 13.19 & 13.19 & 13.19 & 13.19 & 13.04 & 13.19 & 13.19 & 13.19 & 13.19 & 13.08 & 0.71106 \\
& 13.19 & 13.19 & 13.19 & 13.19 & 13.04 & 13.04 & 13.04 & 13.19 & 13.33 & 13.33 & & \\
\end{tabular}

$\sum \mathrm{E}=5.11458$

As a result, $E V=1.25 \mathrm{~N}$ was calculated. This value covers all the variations of the measurement that are generated both by the measurement system and by the test rig, including its mechanics and the belt itself. It can be assumed that the reference value $R F$ is the smallest mean value among those found in Table 3 , namely $F=13.08 \mathrm{~N}$. Then repeatability percentage $\% E V$ can be calculated as follows:

$\% E V=\frac{E V}{R F} \cdot 100 \%=\frac{1.25}{13.08} \cdot 100 \%=9.5 \%$.

Since it is usually required that a new measurement procedure should ensure repeatability of $\% E V$ below $10 \%$ (Dietrich \& Schultze, 2011), the obtained result for the proposed measurement system applied in the real-time monitoring of the belt tension appears highly satisfactory.

\section{Concluding remarks}

The performed researches demonstrated that it is possible to perform real-time monitoring of the industrial belt conveyor with a rubber belt. Even though the measurements do not provide results of the actual belt tension, reliable results on its working condition can be collected. First of all, the system enables initial setting of the belt tension, its monitoring and adjustment just-in-time, after some time of work, in frames of the novel concept of Predictive Maintenance. In particular, the system indicated degree of relaxation in the belt material during longer time.

In the terms of measurement system analysis, measurement ucertainty and repeatability of the novel system were checked. The maximal value of Type A expanded uncertainty calculated for the level of confidence $95 \%$ with coverage factor $k_{U}=1.96$ was $U_{95}=0.034 \mathrm{~N}$, below $0.1 \%$ of the actually measured value of $35 \mathrm{~N}$. Repeatability $E V=1.25 \mathrm{~N}$ covered the variations of the results obtained from all three applied strain gauges in the test rig working conditions, and can be thus considered very advantageous. Related to the reference value, repeatability $\% E V=9.5 \%$ can be considered satisfactory.

In the future researches, it will be necessary to perform deeper analysis of the dynamical tensions of the rubber belt and to correlate these data with signals obtained from strain gauges.

Acknowledgement: The researches were not financed by any institutional funds.

\section{References}

Andrejiova, M., Grincova, A., \& Marasova, D. (2021). Identification with machine learning techniques of a classification model for the degree of damage to rubber-textile conveyor belts with the aim to achieve sustainability. Engineering Failure Analysis, 127, 105564. https://doi.org/10.1016/j.engfailanal.2021.105564

Błażej, R., Jurdziak, L., Kozłowski, T., \& Kirjanów, A. (2018). The use of magnetic sensors in monitoring the condition of the core in steel cord conveyor belts - Tests of the measuring probe and the design of the DiagBelt system. Measurement, 123, 48-53. https://doi.org/10.1016/j.measurement.2018.03.051

Błażej, R., Jurdziak, L.P., \& Kawalec, W. (2015). Condition Monitoring of Conveyor Belts as a Tool for Proper Selection of Their Replacement Time. In Chaari F., Zimroz R., Bartelmus W., Haddar M. (Eds.), Advances in Condition Monitoring of Machinery in Non-Stationary Operations. CMMNO 2014. Applied Condition Monitoring, vol 4 (pp. 483-494). Cham: Springer.

Dietrich, E., \& Schultze, A. (2011). Measurement Process Qualification: Gauge acceptance and measurement uncertainty according to current standards. München: Hanser.

Fedorko, G. (2021). Application possibilities of virtual reality in failure analysis of conveyor belts. Engineering Failure Analysis, 128, 105615. https://doi.org/10.1016/j.engfailanal.2021.105615

Grzesiek, A., Zimroz, R., Śliwiński, P., Gomolla, N., \& Wyłomańska, A. (2020). Long term belt conveyor gearbox temperature data analysis - Statistical tests for anomaly detection, Measurement, 165, 108124. https://doi.org/10.1016/j.measurement.2020.108124 
Hou, Ch., Qiao, T., Zhang, H., Pang, Y., \& Xiong, X. (2019). Multispectral visual detection method for conveyor belt longitudinal tear. Measurement, $246-257$. https://doi.org/10.1016/j.measurement.2019.05.010

JCGM 100:2008. Evaluation of measurement data - Guide to the expression of uncertainty in measurement. Sèvres: Bureau International des Poids et Mesures.

Jeinsch, T., Sader, M., Ding, S.X., Engel, P., Jahn, W., \& Niemz, R. (2000). A Model-Based Information System for Simulation and Monitoring of Belt Conveyor Systems. IFAC Proceedings Volumes, 33(26), 637642. https://doi.org/10.1016/S1474-6670(17)39217-0

Jozić, S., Bajić, D., Dumanić, I., \& Bagavac, Ž. (2021). Optimization for an efficient and highly productive turning process. Reports in Mechanical Engineering, 2(1), $212-221$. https://doi.org/10.31181/rme2001021212j

Kobayashi, Y., \& Toya, K. (2007). Effect of belt transport speed and other factors on belt mistracking. Microsystem Technologies, 13, 1325-1330. https://doi.org/10.1007/s00542-006-0357-y

Liu, X., He, D., Lodewijks, G., Pang, Y., \& Mei, J. (2019). Integrated decision making for predictive maintenance of belt conveyor systems. Reliability Engineering \& System Safety, 188, 347-351. https://doi.org/10.1016/j.ress.2019.03.047

Mazurkiewicz, D. (2015). Maintenance of belt conveyors using an expert system based on fuzzy logic. Archives of Civil and Mechanical Engineering, 15, 412-418. https://doi.org/10.1016/j.acme.2014.12.009

Mörth, O., Emmanouilidis, Ch., Hafner, N., \& Schadler, M. (2020). Cyber-physical systems for performance monitoring in production intralogistics. Computers \& Industrial Engineering, 142, 106333. https://doi.org/10.1016/j.cie.2020.106333

Noack, R., Arloth, J., \& Mendyka, P. (2017). Modeling examples of the mechanical and drive related dynamics of belt conveyors using SimulationX software. Napędy i Sterowanie, 19(11), 94-102. (in Polish).

Rucki, M., Siemiątkowski, Z., Ryba, T., Bzinkowski, D., \& Solecki, M. (2020). Design and calibration of the system supervising belt tension and wear in an industrial feeder. Facta Universitatis Series: Mechanical Engineering, paper in Press. https://doi.org/10.22190/FUME201004026R

Ryba, T. (2021). Initial tests of the rubber belts tension of conveyors with a prototype measuring system. Mechanik, 1, 20-22. https://doi.org/10.17814/mechanik.2021.1.2 (in Polish).

Rybicka, I.K., \& Caban, J. (2020). The Use of a Plate Conveyor for Transporting Aluminum Cans in the Food Industry. Advances in Science and Technology Research Journal, 14(1), $26-31$. https://doi.org/10.12913/22998624/113283

Semrád, K., Draganová, K., Koščák, P., \& Čerňan, J. (2020). Statistical prediction models of impact damage of airport conveyor belts. Transportation Research Procedia, 51, 11-19. https://doi.org/10.1016/j.trpro.2020.11.003

Tyczyński, P., Siemiątkowski, Z., Bąk, P., Warzocha, K., Rucki, M., \& Szumiata, T. (2020). Performance of Maraging Steel Sleeves Produced by SLM with Subsequent Age Hardening. Materials, 13, 3408. https://doi.org/10.3390/ma13153408

Van Etten, M.C. (2017). Application of Conveyors in Mining Industry. Delft: Delft University of Technology.

Wodecki, J., Zdunek, R., Wyłomańska, A., \& Zimroz, R. (2017). Nonnegative factorization of spectrogram for local damage detection of belt conveyor gearboxes. IFAC-Papers OnLine, 50(1), 4714-4718. https://doi.org/10.1016/j.ifacol.2017.08.859

Wu, W., Lu, J., \& Zhang, H. (2019). Smart Factory Reference Architecture Based on CPS Fractal. IFACPapersOnLine, 52(13), 2776-2781.

Yang, M., Zhou, W., \& Song, T. (2020). Audio-based fault diagnosis for belt conveyor rollers. Neurocomputing, 397, 447-456. https://doi.org/10.1016/j.neucom.2019.09.109

Yeh, T.M., \& Sun, J.J. (2013). Using the Monte Carlo Simulation Methods in Gauge Repeatability and Reproducibility of Measurement System Analysis. Journal of Applied Research and Technology, 11, 5, 780796, https://doi.org/10.1016/S1665-6423(13)71585-2 
Zanobini, A., Sereni, B., Catelani, M., \& Ciani, L. (2016). Repeatability and Reproducibility techniques for the analysis of measurement systems. Measurement, 86, 125-132, https://doi.org/10.1016/j.measurement.2016.02.041

Zenisek, J., Wild, N., \& Wolfartsbergerand, J. (2021). Investigating the Potential of Smart Manufacturing Technologies. Procedia Computer Science 180, 507-516. https://doi.org/10.1016/j.procs.2021.01.269

Zhang, J.Z., Srivastava, P.R., Sharma, Dh., \& Eachempati, P. (2021). Big data analytics and machine learning: A retrospective overview and bibliometric analysis. Expert Systems with Applications, 184, 115561. https://doi.org/10.1016/j.eswa.2021.115561

Zhao, L., \& Lin, Y. (2011). Typical failure analysis and processing of belt conveyor. Procedia Engineering, 26, 942-946. https://doi.org/10.1016/j.proeng.2011.11.2260 